
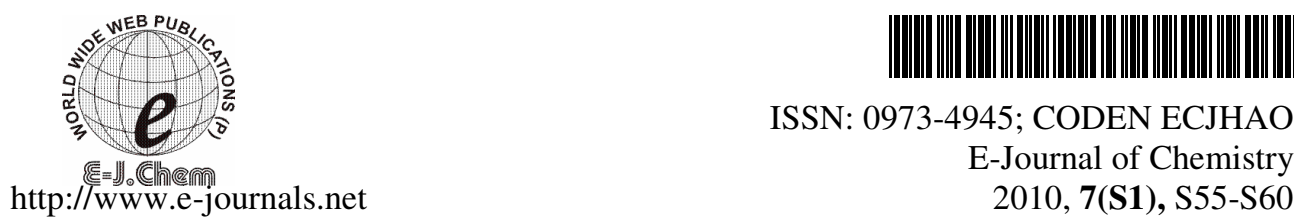

ISSN: 0973-4945; CODEN ECJHAO

E-Journal of Chemistry

2010, 7(S1), S55-S60

\title{
Novel Surface Coating System Based on Maleated Shellac
}

\author{
HASMUKH S. PATEL ${ }^{*}$ and SUMEET J. PATEL \\ Department of Chemistry, Sardar Patel University \\ Vallabh Vidyanagar - 388120 Gujarat, India \\ hsp13152@ rediffmail.com
}

Received 10 January 2010; Revised 31 March 2010; Accepted 21 April 2010

\begin{abstract}
Shellac a natural forest product was reacted with various proportion of maleic anhydride. The resulted maleated shellac samples were designated as (MS-1 to 3) and applied for the preparation of surface coating material. Thus various compositions of coating materials were prepared by varying the contents of MS and commercial grades of acrylic resins (AR). The coating materials were applied on substrates like plaster of paris, cement and limed surface. All the coating showed film performance with good adhesion finish, smoothness and lack of flaking on the surfaces. The results show that the coating showed good water and chemical resistance.
\end{abstract}

Keywords: Acrylic resins, Maleated shellac, Coating, Cement.

\section{Introduction}

Now a day's most of buildings are protected and decorated by water borne paints. The wide uses of these paints mainly due to their ease of applications, fast drying, non-odour, good washability and excellent finish. Non use of organic solvents in these paints, the research has been directed towards eco-friendly water-thinnable paints.

Synthetic resins like acrylic, urethane and epoxy are utilized in the manufacturing of water borne paints. Shellac is a natural product and it is important due to smooth, hard and glossy film with high adherency so its many application like adhesives, surface coating, ink, and in pharmaceutical ${ }^{1-9}$. It is soluble in dilute alkali and its brittleness and poor chemical resistance. It has limited use in paints for building surfaces ${ }^{10-12}$. Acrylic resin is known to be a world wide selected material for water borne paints and thus it's consumption for paints is remarkable. The present authors reported recently the glass reinforced material based on maleated shellac - epoxy resin system ${ }^{13}$. If such MS will blend with acrylic resin it would give good emulsion for coating of cementation surfaces. Hence the present paper describes coating preparation of maleated shellac-acrylic resin emulsion paints, acrylic resin its application as surface coating materials and characteristic. 


\section{Experimental}

Shellac (kusum lac) from Gujarat State Forest Development Crop. Ltd. Baroda, Acrylic Resin (60 percent) solid content as obtained from Champion Paints, Vitthal Udhyog Nagar, Vallabh Vidyanagar, Maleic anhydride, Liquor ammonia solution and triethylamine are used as laboratory grade.

\section{Preparation of aqueous maleated shellac (MS) solution}

The maleated shellac samples were prepared by treatment of shellac with maleic anhydride method reported in our earlier communication ${ }^{14}$. The process is as follow: A solution of shellac $(40 \mathrm{~g})$ in tetrahydrofuran (THF) $(150 \mathrm{~mL})$, various proportions $(10-30 \%$ wt of shellac) of maleic anhydride (not beyond the total hydroxy value) were added and well stirred. The resultant reaction mixture was refluxed for $5 \mathrm{~h}$, cooled and poured into cold water. The resin was obtained as pasty mass. Three samples of MS were prepared and designated as MS-1 to MS-3 (Table 1). A maleated shellac samples (MS-1 to MS-3) were dissolved in required quantity of distilled water containing liquor ammonia solution and triethylamine. The mixture was heated till maleated shellac (MS-1 to MS-3) swells and goes in to solution.

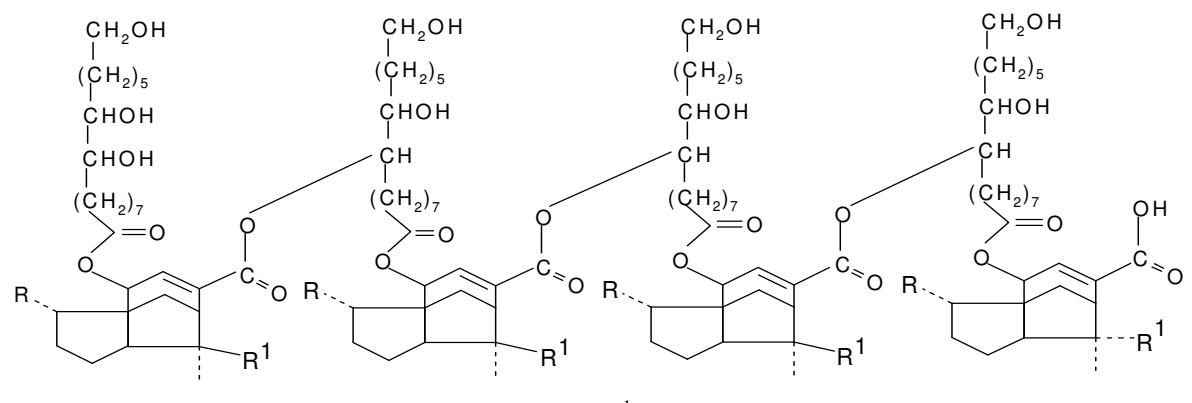

$$
\mathrm{R}=\mathrm{CHO} / \mathrm{COOH}_{1} \mathrm{R}^{1}=\mathrm{CH}_{2} \mathrm{OH} / \mathrm{CH}_{3}
$$

Figure 1. Shellac ${ }^{15}$

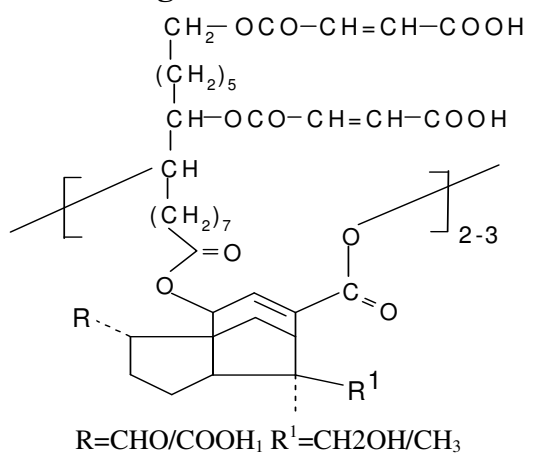

Figure 2. Maleated shellac (MS)

Table 1. Acid value of maleated shellac samples

\begin{tabular}{ccc}
\hline $\begin{array}{c}\text { Sample } \\
\text { (Designation) }\end{array}$ & Reaction mixture & $\begin{array}{c}\text { Acid Value } \\
\text { mg of KOH/gm }\end{array}$ \\
\hline MS-1 & Shellac + 10\% Maleic anhydride & 94 \\
MS-2 & Shellac + 20\% Maleic anhydride & 119 \\
MS-3 & Shellac + 30\% Maleic anhydride & 145 \\
\hline
\end{tabular}




\section{Blending of aqueous (MS) solution with acrylic resin}

Acrylic resin (70 parts) was blended with aqueous maleated shellac samples solution (MS-1 to MS-3) (30 parts) and stirred well to disperse properly. Blending of aqueous solution of MS-1 to MS-3 with acrylic resin samples are designated as MS1-A to MS3-A (Table 2).

Table 2. Designation and coating composition of samples

\begin{tabular}{cc}
\hline $\begin{array}{c}\text { Sample } \\
\text { (Designation) }\end{array}$ & \multicolumn{1}{c}{ Surface Coating Compositions } \\
\hline MS1-A & Maleated Shellac-1 (30\%) + Acrylic Resin (70\%) \\
MS2-A & Maleated Shellac-2 (30\%) + Acrylic Resin (70\%) \\
MS3-A & Maleated Shellac-3 (30\%) + Acrylic Resin (70\%) \\
\hline
\end{tabular}

\section{Preparation of emulsion paint}

Titanium dioxide, calcium carbonate, carboxy methyl cellulose sodium salts, sodium silicate and ethylene glycol were mixed in required quantity with the resin blend and milling was performed thoroughly to make proper emulsion, which could be diluted with water to the desired consistency. A small quantity of strainers was added to obtain different shades of the paint ${ }^{8}$.

The emulsion paint prepared was applied on plaster of paris coated surface, cement surfaces, limed surfaces, by brush and by applicator for testing of the film performance of the paints. Film properties are studied following standard methods for plastic emulsion paint. All the tests were also carried out for one commercial sample simultaneously and results were compared.

\section{Measurement}

\section{Determination of drying time}

Drying time was determine as per IS: 5411 (Part-I)-1974 on plaster of paris coated surface. First coat of the material was applied followed by second coat after interval of $1 \mathrm{~h}$ and the time taken for drying of the second coat was recorded.

\section{Determination of water resistance}

Water - resistance was tested on glass slide RCC plate at room temperature for different interval of time.

\section{Determination of acid and alkali resistance}

Resistance towards acid and alkali was determined by standard procedure on glass slide and RCC plate described as follows. Films of emulsion paint was made on glass slide and RCC plate, dried and dipped in 0.1 percent solution of $\mathrm{HCl}$ and $\mathrm{NaOH}$ solution.

In another experiment, half of the RCC plate was coated with an alkali resistant primer and modified shellac based emulsion paint was applied on full RCC plate. Panels were dried for $168 \mathrm{~h}$ at ambient temperature, the panels was kept on wet filter paper in such a way that both ends of filter paper were dipped in the water.

\section{Wet abrasion testing}

The experiment was carried out by wet abrasion apparatus (WAA 5562, England) on glass plate. Glass plate was first coated with baking type alkali resistant coating, followed by rubbing with emery paper to remove glass of the primer coating material was applied by film applicator (0.006) an dried for $168 \mathrm{~h}$ before conducting the test. 


\section{Results and Discussion}

Acrylic resin was blended carefully with MS. That blending of a polymer with shellac involves intimate mixing between the two components. Thus maleated shellac solutions mixed well with acrylic resin in all proportions afford clear and homogenous blends. Adhesion and finish film were obtained with smoothness and no visible damage and detachment of the film was observed. Films became dry within the limitations of BIS specification.

The coated panels were immersed in water for 5 months and it was observed that there is no effect of detachment, discoloration, etc. On the coating after taking out the panels from water. It was also observed that water, socked by the panels, evaporated when kept at room temperature. No deterioration water socked panels of the coating was noticed and indicating that the composition did not hold the water/ moisture within the system. This is an important characteristic of the paint formulation.

No effect was observed by dipping the coated glass panels in 0.1 per cent $\mathrm{HCl}$ solution. In the case of alkali resistance, no effect was observed on panels. Alkali resistance of the developed product was also tested by dipping the coated panel in 0.5 percent $\mathrm{KOH}$ solution. Film of the maleated shellac - acrylic composition MS1-A, MS2-A, MS3-A coated on slides, remained unaffected up to $18 \mathrm{~h}$. Alkali resistance was also tested as per BIS specification, no effect (colour, change, efflorescence, etc.) was observed. In another experiment, panels coated with the paint composition were washed with a neutral liquid detergent labolene solution (qualigens) to remove the dirt deposited on the coated panels, due to prolonged exposure to atmosphere, showed no effect on paint indicating its good washability. Temperature stability test was carried our as per BIS specification (at $-5 \pm 2{ }^{\circ} \mathrm{C}$ and $60 \pm 5^{\circ} \mathrm{C}$ for $48 \mathrm{~h}$ ). Performance of maleated shellac acrylic emulsion paints composition was found tobe satisfactory. The maleated shellac - acrylic resin based composition and also the commercial paints did not pass the wet abrasion test. The comparative results of the sample prepared with the commercial sample are given in the Table 3.

Table 3. Characteristics of maleated shellac acrylic resin based water thinkable composition and commercial samples

\begin{tabular}{|c|c|c|c|c|c|}
\hline Characteristic & IS Specification & MS1-A & MS2-A & MS3-A & $\begin{array}{c}\text { Commercial } \\
\text { Sample }\end{array}$ \\
\hline Consistency & $\begin{array}{l}\text { Smooth and uniform } \\
\text { and suitable for } \\
\text { application by } \\
\text { appropriate method }\end{array}$ & $\begin{array}{l}\text { Smooth } \\
\text { and } \\
\text { uniform }\end{array}$ & $\begin{array}{l}\text { Smooth } \\
\text { and } \\
\text { uniform }\end{array}$ & $\begin{array}{l}\text { Smooth } \\
\text { and } \\
\text { uniform }\end{array}$ & $\begin{array}{l}\text { Smooth and } \\
\text { uniform }\end{array}$ \\
\hline $\begin{array}{l}\text { Drying time, max } \\
\text { surface dry hard dry }\end{array}$ & $15 \min 4 h$ & $\begin{array}{l}12 \min \\
\text { passes }\end{array}$ & $\begin{array}{l}12 \mathrm{~min} \\
\text { passes }\end{array}$ & $\begin{array}{l}11 \mathrm{~min} \\
\text { passes }\end{array}$ & $\begin{array}{l}12 \mathrm{~min} \\
\text { passes }\end{array}$ \\
\hline Finish & $\begin{array}{l}\text { Smooth and matt or } \\
\text { egg-shell } \\
\text { finish }\end{array}$ & $\begin{array}{l}\text { Smooth } \\
\text { and } \\
\text { Matt finish }\end{array}$ & $\begin{array}{l}\text { Smooth } \\
\text { and matt } \\
\text { finish }\end{array}$ & $\begin{array}{l}\text { Smooth } \\
\text { and matt } \\
\text { finish }\end{array}$ & $\begin{array}{l}\text { Smooth and } \\
\text { matt finish }\end{array}$ \\
\hline $\begin{array}{l}\text { Resistance to wet } \\
\text { abrasion and } \\
\text { washing (average) }\end{array}$ & $\begin{array}{l}\text { To pass the test } \\
\text { (4000 oscillations) }\end{array}$ & 150 & 154 & 174 & 180 \\
\hline Resistance to alkali & To pass the test & Passes & Passes & Passes & Fails \\
\hline $\begin{array}{c}\text { Temperature stability at } \\
-5 \pm 1{ }^{0} \mathrm{C} \text { for } 48 \mathrm{~h} \text { at } 60 \\
\pm 1{ }^{0} \mathrm{C} \text { for } 48 \mathrm{~h}\end{array}$ & To pass the test & Passes & Passes & Passes & Passes \\
\hline $\begin{array}{l}\text { Keeping property } \\
\text { resistance to water } \\
\text { (continuous immersion) }\end{array}$ & Not less than 1 year & $\begin{array}{c}\text { Passes } \\
>5 \text { months }\end{array}$ & $\begin{array}{c}\text { Passes } \\
>5 \text { months }\end{array}$ & $\begin{array}{l}\text { Passes } \\
>5 \text { months }\end{array}$ & $\begin{array}{l}\text { Passes } \\
>4 \text { months }\end{array}$ \\
\hline
\end{tabular}


Viscosity of all samples was observed with time. It results are almost same or near about, it indicate that good leveling capability and absence of sagging of the composition (Table 4). A Small change in the solution viscosity with temperature was observed between 30 and $45^{\circ} \mathrm{C}$ increased flow with temperature (Table 5).

Table 4. Viscosity of maleated shellac acrylic resin surface coating material with time at $25{ }^{\circ} \mathrm{C}$

\begin{tabular}{ccc}
\hline Designation & Time, sec & Viscosity, pas \\
\hline & 50 & 0.0105 \\
MS1-A & 100 & 0.0107 \\
& 150 & 0.0105 \\
& 200 & 0.0106 \\
& 250 & 0.0108 \\
\hline MS2-A & 50 & 0.0107 \\
& 100 & 0.0106 \\
& 150 & 0.0109 \\
MS3-A & 200 & 0.0108 \\
& 250 & 0.0106 \\
\hline & 50 & 0.0106 \\
& 100 & 0.0108 \\
& 200 & 0.0107 \\
& 250 & 0.0108 \\
\hline
\end{tabular}

Table 5. Variation of viscosity with temperature of maleated shellac acrylic resin surface coating material

\begin{tabular}{ccc}
\hline Designation & Temperature, ${ }^{0} \mathrm{C}$ & Viscosity, pas \\
\hline \multirow{3}{*}{ MSA-1 } & 30 & 0.061 \\
& 35 & 0.040 \\
& 40 & 0.035 \\
MSA-2 & 45 & 0.031 \\
& 30 & 0.063 \\
& 35 & 0.043 \\
& 40 & 0.038 \\
MSA-3 & 45 & 0.033 \\
& 30 & 0.065 \\
& 35 & 0.042 \\
& 40 & 0.038 \\
\hline
\end{tabular}

In the present cases both compounds as compatible as both have carboxylic groups. It is expected that blending of MS with acrylic resin might lead to the polymerization and/or cross linking between the two components through unsaturation which resulted in to excellent resistance towards water and fairly good resistance to alkali despite shellac alone blushes and becomes easily soluble when it comes in to contact with water and alkali, respectively.

\section{Acknowledgment}

We would like to thank the Forest Division, Gandhinagar for the grant providing the financial assistance. We are also grateful to Dr. (Miss) R.G.Patel, Head, Department of Chemistry, for providing the necessary research facilities. 


\section{References}

1. Maiti S and Rahman M S, J Macromole Sci Rev Macromole Chem Phy., 1986, C26, 441.

2. Goswami D N, Singh D D and Baboo B, Paint India, 2008, LVIII (2), 88, 67-70,

3. Kumar S and Sankarnarayanan Y, Indian Patent, 1965, 88878.

4. Bhadani S N, Kumari M and Sen Gupta S K, J Appl Polymer Sci., 1993, 49(8), 1471-1474.

5. Goswami D N, Jha P C and Mahato K, Indian J Chem Technol., 2004a, 11, 67-73.

6. Goswami D N, Prasad N, Jha P C and Mahato K, Indian J Chem Technol., 2004b, 11, 121-126.

7. $\quad$ Krause K P and Muller R H, Int J Pharm., 2001, 223(1-2), 89-92.

8. Mcguire R G and Hagenmaier R D, Biological Control, 1996, 7(1), 100-106.

9. Casson N, in C.C Mill. (Ed.), Rheology of Disperse Systems, Pergamon Press, London, 1959, 84.

10. Mukhrerjee M and Kumar S, Research and Industry, 1982, 27, 233-236.

11. Dasgupta A K, Kumar S and Chatterjea J N, J Colour Soc., 1982, 21(2), 37.

12. Chopra S S and Sankarnarayanan Y, Indian J Technol., 1967, 50(6), 190-193.

13. Patel H S and Patel S J, J Reinforced Plastics and Composites, 2009, doi: 10.1177/0731684409103336.

14. Martens C R, Emulsion and Water-Soluble Paints and Coatings, Reinhold Publishing Corporation, New York, NY 1965.

15. Singh H, Madhav R, Seshadri T R and Subramanian G B V, Tetrahedron, 1967, 23(12), 4795-4800. 


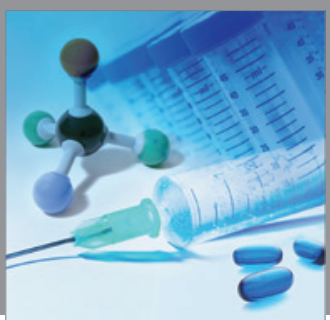

International Journal of

Medicinal Chemistry

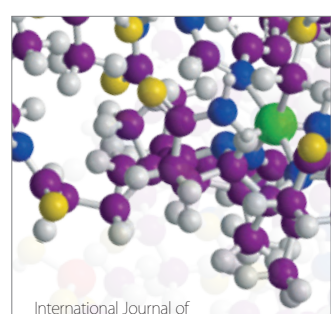

Carbohydrate Chemistry

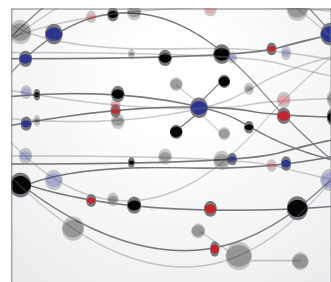

The Scientific World Journal
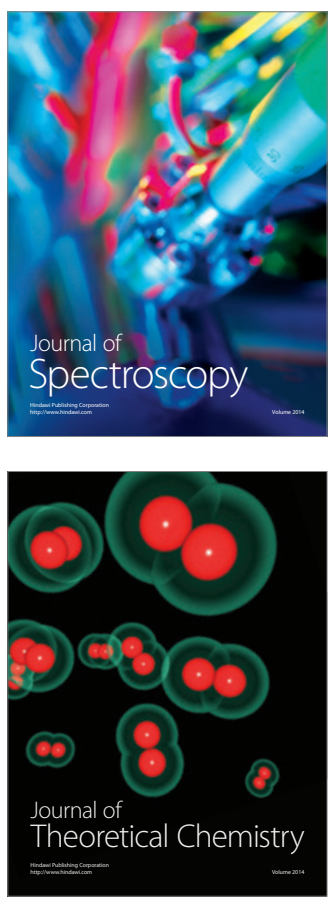
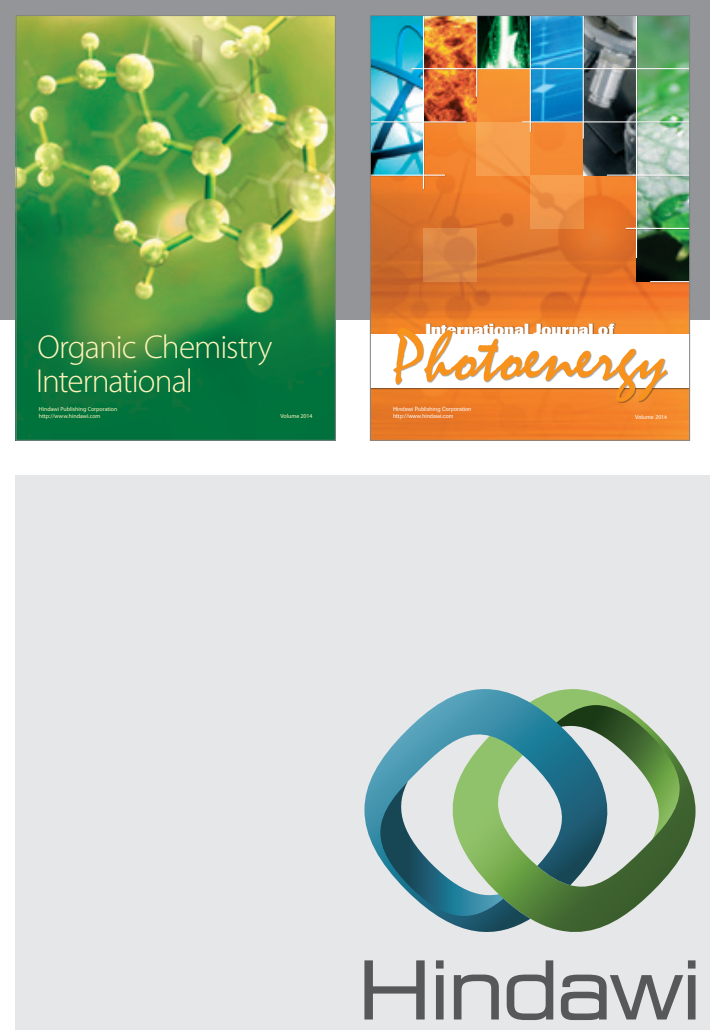

Submit your manuscripts at

http://www.hindawi.com
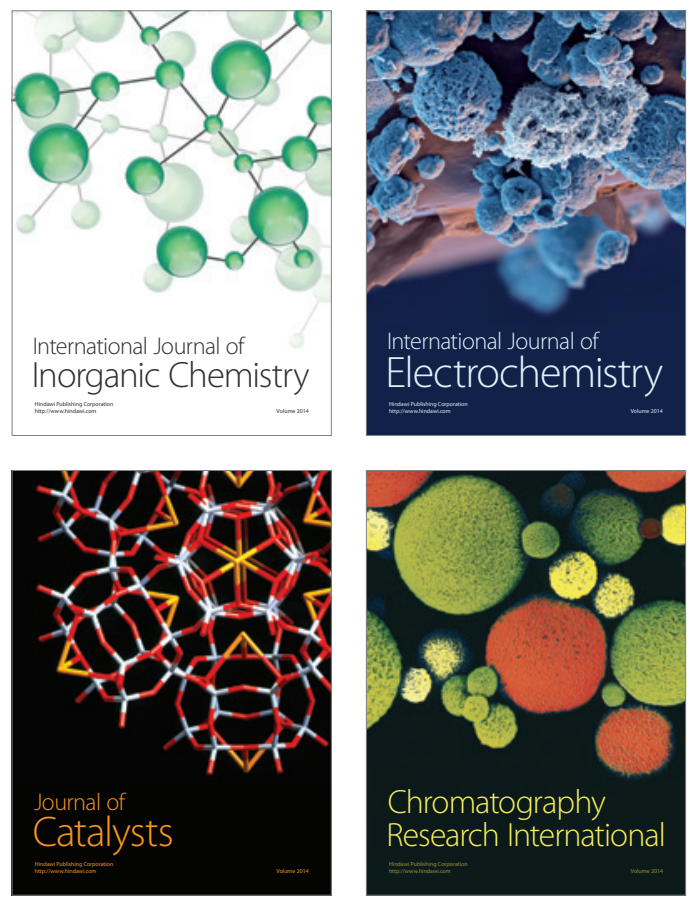
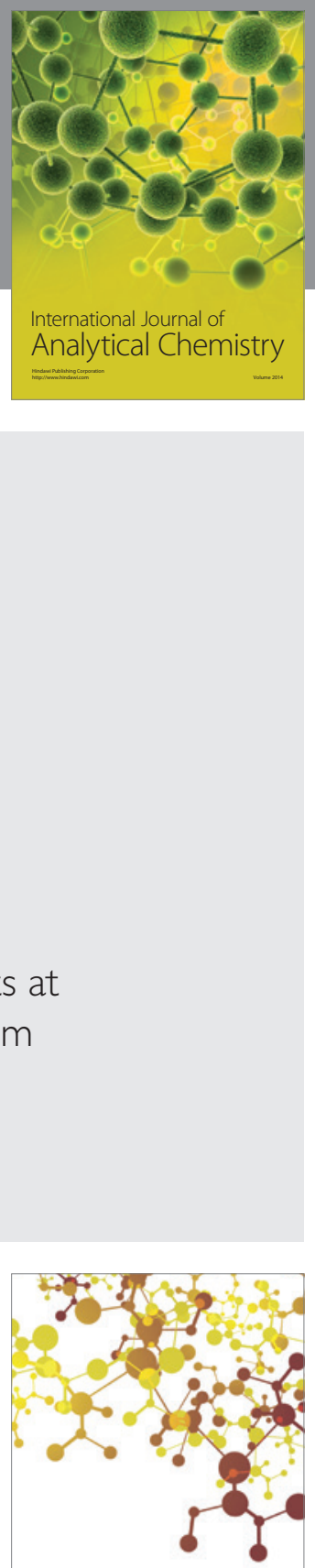

Journal of

Applied Chemistry
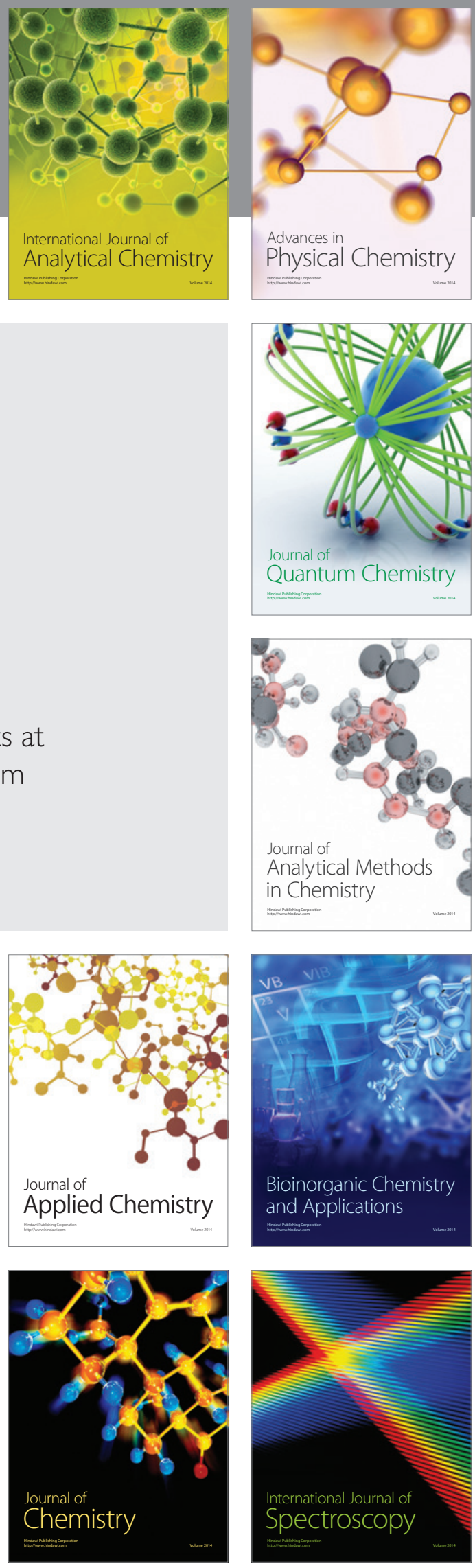